\title{
Variability in mesophotic coral reef communities along the Great Barrier Reef, Australia
}

\author{
Thomas C. L. Bridge ${ }^{1, *}$, Terence J. Done ${ }^{2}$, Ariell Friedman ${ }^{3}$, Robin J. Beaman ${ }^{4}$, \\ Stefan B. Williams ${ }^{3}$, Oscar Pizarro ${ }^{3}$, Jody M. Webster ${ }^{5}$ \\ ${ }^{1}$ School of Earth and Environmental Sciences, James Cook University, Townsville, Queensland 4811, Australia \\ ${ }^{2}$ Australian Institute of Marine Science, Townsville, Queensland 4810, Australia \\ ${ }^{3}$ Australian Centre for Field Robotics, University of Sydney, Sydney, New South Wales 2006, Australia \\ ${ }^{4}$ School of Earth and Environmental Sciences, James Cook University, Cairns, Queensland 4870, Australia \\ ${ }^{5}$ School of Geosciences, University of Sydney, Sydney, New South Wales 2006, Australia
}

\begin{abstract}
The composition of sessile benthic megafauna communities on mesophotic coral reefs (50 to $65 \mathrm{~m}$ depth) was investigated at 3 sites (Noggin Pass, Viper Reef and Hydrographers Passage) over $500 \mathrm{~km}$ of the Great Barrier Reef (GBR) shelf-edge, Australia. High-resolution stereo imagery was collected in 4 separate autonomous underwater vehicle (AUV) surveys and used to characterise the substratum and megafauna at each site (2 surveys from Viper Reef, and one from each of Noggin Pass and Hydrographers Passage). Random sampling of 100 images from a $100 \times 100 \mathrm{~m}$ area at each site indicated that non-reef habitats predominated and that megafauna were largely confined to reef habitats, while a more detailed investigation of these reef substrata revealed diverse benthic megafaunal communities that varied significantly both within and between study sites. There were consistent patterns in the functional ecological groups occupying particular finer-scale habitat types, with phototrophic taxa dominating the flatter tops of submerged reefs and heterotrophic suspensionfeeders occupying steeper habitats. Slope angle, water clarity and productivity best explained the distribution of megafauna on reef habitats. Reduced photosynthetically active radiation (PAR) likely excludes most phototrophic taxa from steeper slopes. These results suggest that the extensive submerged reefs on the outer-shelf of the GBR harbour diverse mesophotic reef communities. Given these results, GBR mesophotic coral ecosystems deserve further study, not only of their benthic megafauna but also their fish and mobile invertebrate communities.
\end{abstract}

KEY WORDS: Mesophotic $\cdot$ Coral $\cdot$ Octocoral $\cdot$ Community composition $\cdot$ Autonomous underwater vehicle $\cdot$ AUV $\cdot$ Great Barrier Reef

\section{INTRODUCTION}

The Great Barrier Reef (GBR) extends $\sim 2300 \mathrm{~km}$ along Australia's north-east coast (Hopley et al. 2007). Although the iconic emergent reefs are widely recognised, a vast submerged barrier reef system also occurs on the shoulder of the continental shelf and may be as long as the emergent GBR. A continuous line of submerged reefs has been documented occurring for over $800 \mathrm{~km}$ in the central GBR in 50 to $70 \mathrm{~m}$ water depth (Hopley et al. 1997, Hopley 2006). Submerged reefs have also been mapped on the steeper shelf margin of the northern GBR (Beaman et al. 2008) and also in the far north near Torres Strait (Harris et al. 2005). Studies on these reefs generally focussed on their geomorphology (Harris \& Davies 1989, Hopley 2006, Beaman et al. 2008); consequently, little is known about their ecology.

Mesophotic coral ecosystems (MCEs) are tropical coral reef communities that exist from $\sim 30 \mathrm{~m}$ to the bottom of the photic zone, often exceeding $100 \mathrm{~m}$ in depth (Kahng et al. 2010). In recent years, they have been receiving increased attention from both scientists and managers due to an increasing awareness of both their 
intrinsic ecological character and biodiversity, and their potential to act as refugia for coral reef species as these areas become exposed to damaging environmental changes, such as rising sea surface temperatures and increasing incidence of severe cyclones (e.g. Bongaerts et al. 2010). Studies of MCEs have been conducted in the Caribbean and the Red Sea (Fricke et al. 1987) as well as several locations in the Indo-Pacific, including Johnston Atoll (Maragos \& Jokiel 1986), Enewetak (Colin 1986, Colin et al. 1986), American Samoa (Bare et al. 2010) and Hawaii (Kahng \& Kelley 2007).

The vast majority of studies conducted on coral reefs worldwide have focussed on shallow-water habitats $<30 \mathrm{~m}$ deep, with the lower depth limit largely imposed by the use of SCUBA. Recent technological advances, such as multibeam sonar and autonomous underwater vehicles (AUVs) (e.g. Armstrong et al. 2006, Williams et al. 2010) have enabled the collection of remotely-sensed data in deep water habitats and at multiple spatial scales. Moreover, use of such remotely sensed data to predict the distribution of benthic communities has greatly increased, particularly over large geographical areas (e.g. Kostylev et al. 2001, Mumby et al. 2004, Beaman \& Harris 2007, Pitcher et al. 2007).

The distribution of MCEs across various spatial scales is determined by a combination of environmental factors including geomorphology, sedimentation, light availability, and temperature gradients (Locker et al. 2010). However, the effect of these variables on MCE community structure remains poorly understood, particularly in the vastly understudied MCEs of the Indo-Pacific (Hinderstein et al. 2010, Kahng et al. 2010). Variations in physical water properties - such as wave energy, water clarity, productivity, and sedimentation - both across and along the GBR shelf have been correlated with changes in community composition of shallow-water reef taxa including corals (Done 1982) and octocorals (Dinesen 1983, Fabricius \& De'ath 2008). Coral species richness decreases with increasing latitude south along the length of the GBR (Veron 1995). However, changes in the composition of many communities are greater across-shelf, from turbid coastal habitats to the clear oceanic waters of the outer-shelf. Done (1982) showed coral community composition and richness varying across the central GBR both within and between reefs in response to predictable environmental parameters. On shallow-water reefs, overall diversity for both corals and octocorals peaks mid-shelf (Done 1982, Fabricius \& De'ath 2008), although the distribution of octocorals varies substantially between phototrophic and heterotrophic taxa. Phototrophic octocorals in the GBR occur in a wide range of habitats, whereas heterotrophs exhibit limited ranges with highest richness occurring in regions of high productivity and water flow and low disturbance (Fabricius \& De'ath 2008). An extensive study of continental shelf seabed habitats in the GBR suggests that local species composition and abundance in most biotas on the GBR are in large part driven by the local environment and not strongly correlated to cross-shelf position or latitude per se (Pitcher et al. 2007).

The GBR's submerged shelf-edge reefs are exposed to water that is generally clear and oligotrophic (Wolanski 1994), although modelling of long-term (30 yr) water quality data by De'ath (2007) indicates pelagic productivity doubles from north to south along the length of the GBR outer-shelf. To date, no studies have attempted to examine how different environmental factors may affect community composition of the MCEs. Using the results of a semi-quantitative study at sites separated by up to $\sim 500 \mathrm{~km}$ on the GBR outershelf (see Fig. 1), this study provides the first investigation of possible environmental drivers of mesophotic reef community structure on the GBR. The study aims to (1) determine the structure of sessile benthic megafauna (SBM) communities at 3 sites along the GBR shelf-edge and (2) identify the physical/environmental factors that best explain the distribution patterns of SBM communities.

\section{MATERIALS AND METHODS}

Study sites. Noggin Pass: The Noggin Pass site (10 km east of Noggin Reef at $17.09^{\circ} \mathrm{S}, 146.57^{\circ} \mathrm{E}_{;}$Fig. 1) consists of a series of pinnacles, 20 to $50 \mathrm{~m}$ in diameter, which rise $\sim 3 \mathrm{~m}$ above the surrounding seafloor (Fig. 2a). These structures, occurring at a depth of 58 to $63 \mathrm{~m}$, were interpreted by Webster et al. (2008) as palaeo-patch reefs. A channel occurs immediately to the south of the site, which is located $\sim 700 \mathrm{~m}$ from the shelf break (120 m depth). The shelf itself at this latitude is generally steeper than at the other 2 study sites at Viper Reef and Hydrographers Passage.

Viper Reef: The Viper Reef site $\left(18.83^{\circ} \mathrm{S}, 148.45^{\circ} \mathrm{E}\right.$; Fig. 1) consists of 2 separate AUV surveyed areas located $\sim 650 \mathrm{~m}$ apart: Viper North and Viper South (Fig. 2b). The surveys were conducted $\sim 1000 \mathrm{~m}$ from the shelf break ( 130 m deep) seaward of a line of submerged shoals. These shoals are $\sim 10 \mathrm{~km}$ seaward of the closest emergent outer-shelf reefs (Lion and Jaguar Reefs). The surveys covered two of a series of limestone pinnacles 20 to $80 \mathrm{~m}$ in diameter at a depth of $\sim 56 \mathrm{~m}$ and rising 2 to $5 \mathrm{~m}$ above the surrounding seafloor.

Hydrographers Passage: The Hydrographers Passage study site $\left(19.70^{\circ} \mathrm{S}, 150.25^{\circ} \mathrm{E}\right.$; Fig. 1) is located $12 \mathrm{~km}$ north-east of the nearest emergent outer shelf reef (Rebe Reef). The shelf break is located at $\sim 130 \mathrm{~m}$ and lies nearly $3 \mathrm{~km}$ seaward of the site. The continen- 


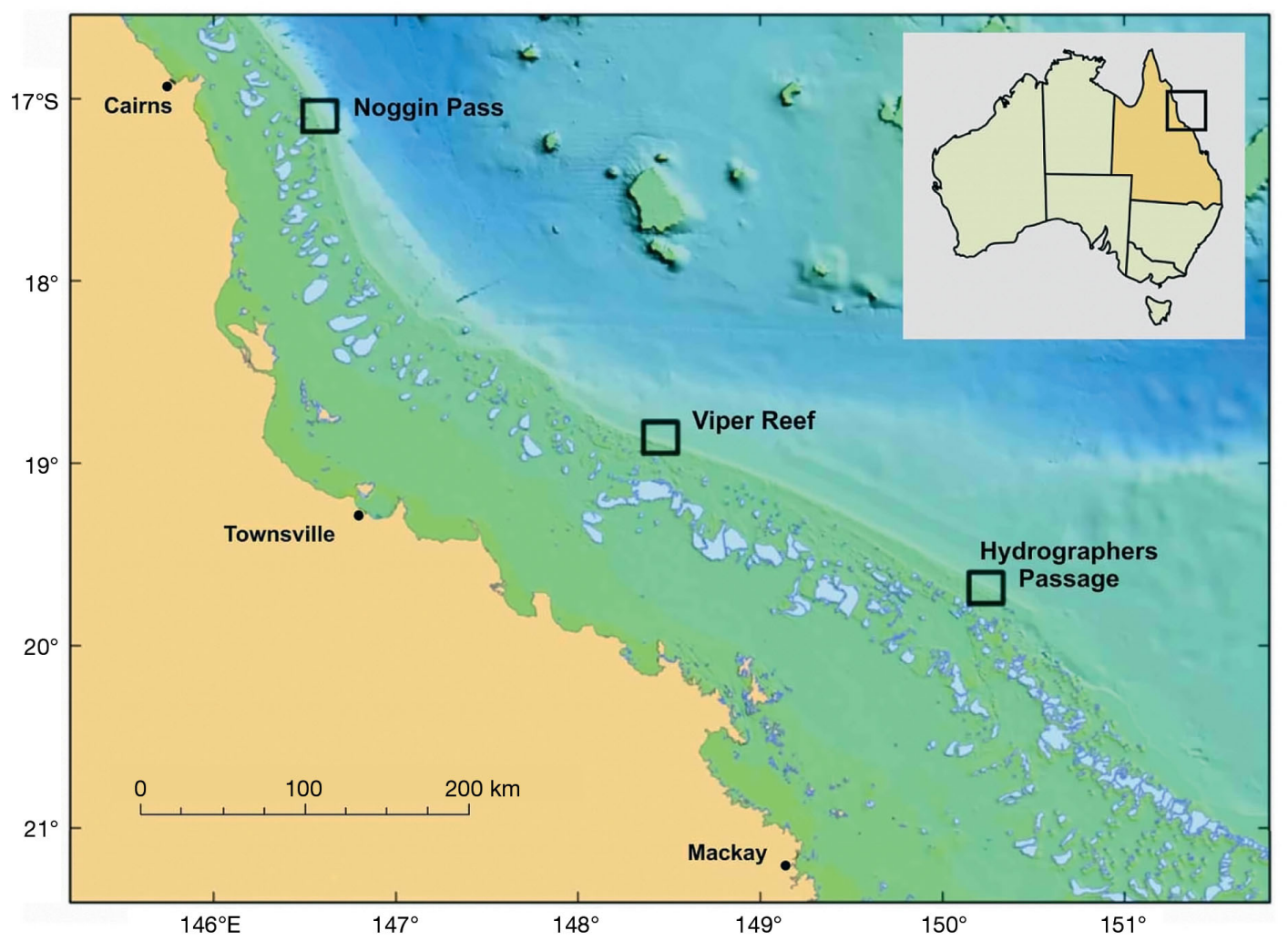

Fig. 1. Study sites along the Great Barrier Reef shelf-edge: Surveys were conducted at Noggin Pass, Viper Reef, and Hydrographers Passage from September to October 2007
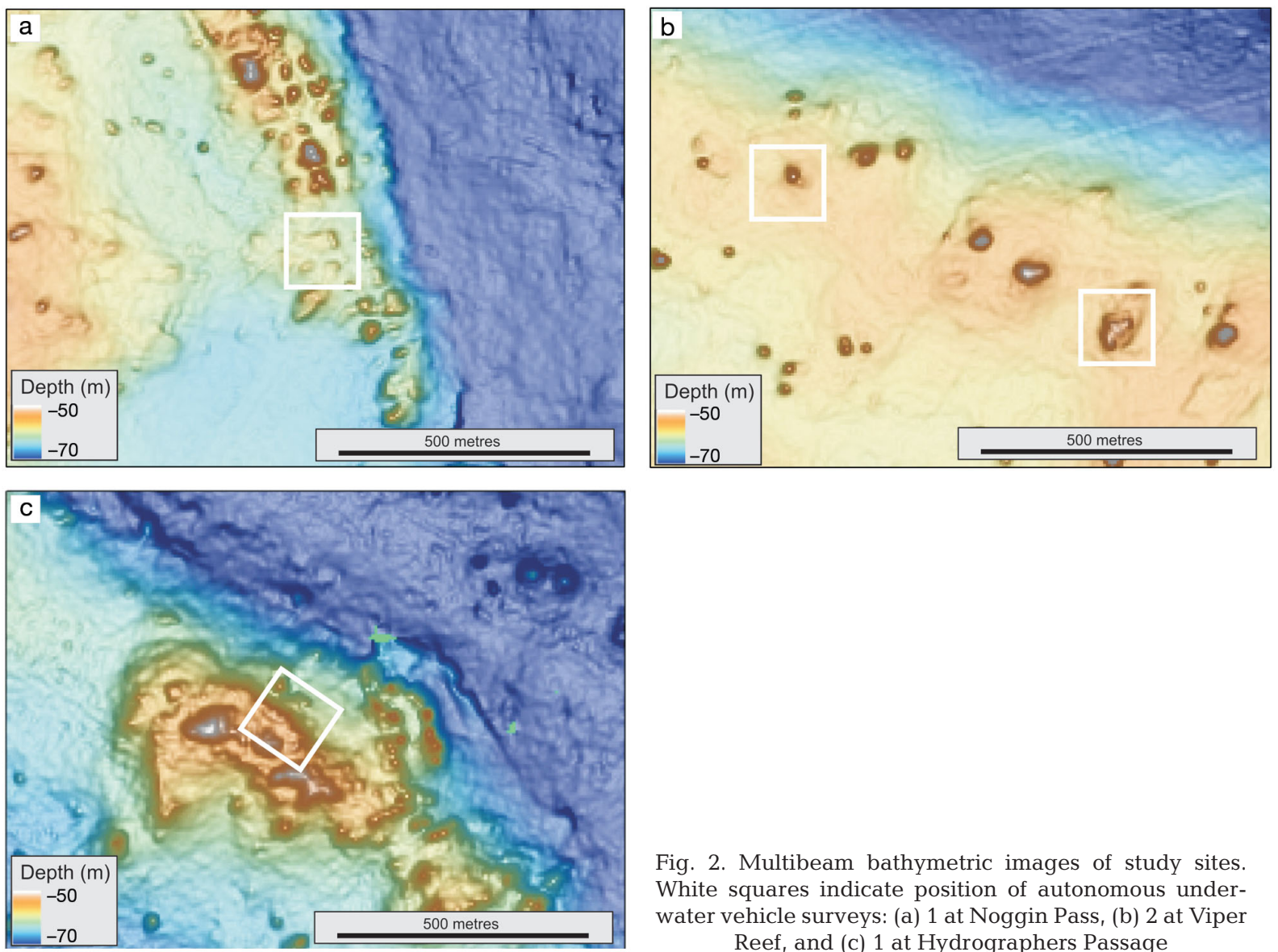

Fig. 2. Multibeam bathymetric images of study sites. White squares indicate position of autonomous underwater vehicle surveys: (a) 1 at Noggin Pass, (b) 2 at Viper Reef, and (c) 1 at Hydrographers Passage 
tal shelf in this area is wider and exhibits a shallower gradient than in the northern study areas (Hopley et al. 1997). The site is in a high-energy region exposed to strong tidal currents with small emergent reefs set back from the shelf edge. A series of submerged coral shoals, located $\sim 12 \mathrm{~km}$ seaward of emergent reefs, have been previously identified by the Great Barrier Reef Marine Park Authority and on nautical charts. The AUV survey (Fig. 2c) was conducted on the seaward edge of a $500 \times 200 \mathrm{~m}$ submerged reef that rises from 62 to $50 \mathrm{~m}$ depth, and included limestone pinnacles $\sim 30 \mathrm{~m}$ in diameter that rise up to $\sim 6 \mathrm{~m}$ above the surrounding sea floor.

Topography. A topographic model of the sea floor at each site was created using multibeam bathymetry data collected using a ship-mounted Kongsberg ${ }^{\mathrm{TM}}$ Simrad EM-300 multibeam sonar system operated at a frequency of $30 \mathrm{kHz}$. Data were processed within Caris $^{\mathrm{TM}}$ HIPS/SIPS software to remove erroneous values and to apply appropriate corrections (e.g. tides and sound velocity), then gridded into a BASE (Bathymetry Associated with Statistical Error) surface at $5 \times 5 \mathrm{~m}$ grid resolution within HIPS/SIPS. The BASE surface pixel values were exported to ASCII xyz (long//lat/depth) files, and gridded within ESRI ${ }^{\mathrm{TM}}$ ArcGIS to create the topographic model in the form of xyz-georeferenced raster layers.

AUV data. High-resolution, georeferenced stereoscopic images of the sea floor were collected at a rate of $2 \mathrm{~Hz}$ using the AUV 'Sirius', which was programmed to travel $2 \mathrm{~m}$ above the sea floor at a speed of $0.45 \mathrm{~m} \mathrm{~s}^{-1}$ (Williams et al. 2010). A total of 4 AUV surveys were conducted across 3 sites; 2 from Viper Reef (6 and 7 October 2007) and one from both Noggin Pass (3 October) and Hydrographers Passage (11 October). The primary aim of the research expedition was to investigate the nature of the submerged reefs from a geological standpoint, specifically to examine changes in reef growth and palaeoenvironmental conditions since the last glacial maximum. The primary role of the AUV was therefore to provide high-resolution images of the reefs themselves (described in Williams et al. 2010) rather than to quantitatively assess the biota, which was a secondary goal of the expedition. Therefore, the analysis in this study required several different surveys conducted for geological purposes to be standardised for ecological analysis. Each survey was conducted using orthogonal line transects. The smallest total area covered by an AUV grid was $100 \times 100 \mathrm{~m}$ (Noggin Pass); therefore, the other AUV surveys were clipped to this size.

Two surveys were conducted at Viper Reef to examine whether proximal sites contained similar megabenthos. Analysis was conducted at 2 spatial scales; initially, a site-scale analysis was conducted by ran- domly selecting 100 images from each survey (400 images in total) over each entire $100 \times 100 \mathrm{~m}$ area. Analysis of these data revealed a high proportion of uninformative 'non-reef' images (sand or graveldominated substrata) containing little or no $\mathrm{SBM}_{\text {; }}$ therefore, a more detailed examination of reef habitats was conducted by randomly selecting supplementary images from 'reef' substrates (defined as $>50 \%$ limestone or sediment-covered limestone). A total of 25 'reef' images were selected from each survey (100 images in total), which was found to be adequate to characterise the richer communities on reef substrata.

The characterisation of megafauna and substrata was made by detailed visual inspection of high-resolution images from the AUV. Data on substrata and biota were collected from each image using ordered abundance categories where $0=$ no occurrence; $1=$ present at $<5 \%$ cover $; 2=5-10 \% ; 3=10-30 \% ; 4=30-80 \%$; and $5=>80 \%$. SBM (Porifera, Scleractinia, Antipatharia, Octocorallia, Actiniaria, Crinoidea and Ascidiacea) were identified to the lowest taxonomic unit reliably achievable from the images (primarily genera, but some species). In some cases (e.g. azooxanthellate octocorals), morphology was used for classification when identification of species or genus was not possible from the AUV images (e.g. fan gorgonian). Rare taxa $(<2 \%$ occurrence), which can create unpredictable relationships with environmental variables (Clarke \& Warwick 2001), were subsequently grouped together into 'morphological units' (MUs) before inclusion in analyses (see Appendix 1).

Abiotic data describing each image and to be used as potential explanatory variables were as follows: the relative abundances of 5 substratum types (sand, gravel, rubble, sediment-covered limestone [SCL] and limestone); zone (classified as crest, depression, slope or flat calculated using the Benthic Terrain Modeller extension for ArcMap 9.x) (Wright et al. 2005); rugosity, slope and aspect (derived from stereo image reconstructions, described in the next paragraph); and productivity and water clarity (estimated for each site using long-term modelled data on chlorophyll and secchi disk measurements).

Three-dimensional triangular mesh terrain reconstructions with $\pm 10 \mathrm{~mm}$ resolution were created for each image using the stereo image pairs combined with information on vehicle position and orientation (Mahon et al. 2008, Johnson-Roberson et. al. 2010) and used to calculate rugosity, slope and aspect (see Friedman et al. 2010). Rugosity was expressed using a rugosity index $(R I)$, calculated by centering a window over each $1.5 \times 1.2 \mathrm{~m}$ AUV stereo image pair and dividing the area of the contoured surface contained within the window by the area of its orthogonal projection onto the plane of best fit. The contoured surface area is 
the sum of the areas of the triangles that make up the surface, and the plane of best fit was found using principal component analysis. An $R I$ value of 1 represents a completely flat surface, and this value increases with increasing fine-scale roughness. Slope $(S)$ refers to the smallest angle between the plane of best fit and the horizontal plane. Fitting a plane to the data removes $S$ from $R I$ and ensures the 2 values are independent; although many rugose habitats also exhibit high slope, a steep flat plane (i.e. a reef wall) can be recognised as having high slope but low rugosity. Aspect $(A)$ refers to the direction that the plane faces, which is measured as the angle between north and the horizontal projection of the vector normal onto the horizontal plane. Aspect values were transformed to harmonics ( $\sin [\mathrm{a}]$ and $\cos [\mathrm{a}])$ and treated as joint variables. Productivity and water clarity values were estimated from models of long-term GBR water quality at each site (see De'ath 2007) and accessed via the AIMS e-atlas (http://e-atlas.org.au/geoserver/wms). Where the model extends only to the edge of the emergent reefs (Viper Reef or Hydrographers Passage), estimates were obtained as close as possible to the study site $(<10 \mathrm{~km}$ in both cases), which was deemed sufficiently accurate, particularly given the GBR-wide scale of the model. Being located on the outer-shelf, all sites were clear and oligotrophic compared to inshore regions. However there was variation between sites: water clarity was highest at Noggin Pass (Secchi depth $=20.1$ ) and lowest at Viper Reef (17). Chlorophyll was twice as high at Hydrographers Passage $(0.67 \mu \mathrm{g} / \mathrm{l})$ than at the 2 more northerly sites $(0.3$ to $0.35 \mu \mathrm{g} / \mathrm{l})$; however, all sites showed much lower chlorophyll levels than areas further inshore. All abiotic variables were normalised (mean $=0$ and $\mathrm{SD}=1$ ) using PRIMER prior to statistical analysis.

Data analysis. Statistical analysis was performed using PRIMER v6 (Clarke \& Gorley 2006). Statistical analysis used in PRIMER was performed on a BrayCurtis similarity matrix (the complement of the dissimilarity matrix, B-C*100), the standard format for PRIMER. The ANOSIM (analysis of similarities) function was performed on a Bray-Curtis similarity matrix of the relative abundances of MUs to determine the relationships and significance of variation observed in the 4 AUV surveys and across the 3 sites. ANOSIM is an approximate analogue for standard univariate 1-way and 2-way ANOVA tests. Similarity percentages (SIMPER) were used to examine the contribution of individual MUs to variations indicated by ANOSIM. Hierarchical cluster analysis was performed to identify image groups based on dominant SBM site groups (Ward's sum of squares index; group-average linkage, after Done 1982). The influence of the abiotic variables on relative abundances of MUs was also tested using the BIOENV function within PRIMER. Spearman rank correlation was used to determine the strength and significance of relationships between the Bray-Curtis similarity matrix (SBM) and a normalised Euclidean distance matrix (based on the abiotic data). Multidimensional scaling (MDS) was used to illustrate the relative similarity among images and sites, as well as the relationship of images and image groups to the explanatory abiotic variables with a Spearman rank correlation >0.5. Shannon's diversity index $\left(H^{\prime}=\right.$ $-\Sigma P_{i}\left[\ln P_{i}\right]$, where $P_{i}$ is the proportion that $\mathrm{MU}_{i}$ contributes to the total score in any one image) was calculated for each image as a measure of its taxonomic diversity.

\section{RESULTS}

\section{Site-scale community structure}

Analysis at the scale of each $100 \times 100 \mathrm{~m}$ site $(400$ images in total) showed that most of the sea floor was 'non-reef' substratum containing very little SBM. By comparison, separate analysis of 'images from reef' substrata revealed abundant and diverse SBM communities occurring in reef habitats. Cluster analysis of the site-scale data (not reproduced here) yielded 5 macrofaunal image groups, of which one, based on shared absences, accounted for $316(79 \%)$ of the images. This group included all the images of 'non-reef' substrata (sand and gravel), of which most were without any SBM at all $(85,96$ and $91 \%$ at Noggin Pass, Viper North, and Viper South, respectively). Hydrographers Passage had fewer images with low SBM cover (44\%). Although not quantitatively scored, algal colonisation of 'non-reef' substrates was observed in the images and varied considerably between sites. The calcareous green alga Halimeda was ubiquitous in 'non-reef' images at Viper Reef. 'Non-reef' areas at Noggin Pass were generally completely bare; however, Halimeda growth was observed on lower reef slopes. Halimeda was scarce at Hydrographers Passage.

\section{Communities on 'reef' substrata}

SBM communities on 'reef' substrata showed considerable variation among all 4 surveys (Table 1). Dominant groups of SBM identified were Porifera (sponges), Scleractinia (hard corals), Antipatharia (black corals) and Octocorallia (soft corals) (Fig. 3, Table 2). Hard corals (particularly Montipora) occurred at all sites, although they were particularly dominant at Viper Reef (Fig. 4a). Hydrographers Passage contained a high diversity of phototrophic octocorals (particularly 
Table 1. Summary of ANOSIM results indicating variation in benthic composition between sites (latitudes) and autonomous underwater vehicle (AUV) surveys on 'reef' substrates. The lower the R-value, the more similar the sites. Latitudes: $17^{\circ} \mathrm{S}$ (Noggin Pass), $19^{\circ} \mathrm{S}$ (Viper Reef), and $20^{\circ} \mathrm{S}$ (Hydrographers Passage). AUV surveys: NP (Noggin Pass), VN (Viper North), VS (Viper South) and HP (Hydrographers Passage)

\begin{tabular}{|lccc|}
\hline & Comparison & R-value & p-value \\
\hline Sites $\left({ }^{\circ} \mathrm{S}\right)$ & $17^{\circ}$ vs. $19^{\circ}$ & 0.541 & 0.001 \\
& $17^{\circ}$ vs. $0^{\circ}$ & 0.289 & 0.001 \\
& $19^{\circ}$ vs. 20 & 0.548 & 0.001 \\
AUV surveys & NP vs. VN & 0.475 & 0.001 \\
& NP vs. VS & 0.488 & 0.001 \\
& NP vs. HP & 0.289 & 0.001 \\
& VN vs. VS & 0.175 & 0.002 \\
& VN vs. HP & 0.373 & 0.001 \\
& VS vs. HP & 0.484 & 0.001 \\
\hline
\end{tabular}

Cespitularia) and the phototrophic sponge Carteriospongia in addition to corals (Fig. 4b). By contrast, the large, distinctive heterotrophic octocoral Annella (Fig. 4c) was particularly abundant at Noggin Pass, but rare elsewhere. Overall, both the richness of MUs and diversity $\left(H^{\prime}\right)$ was highest at Hydrographers Passage (32 MUs, $H^{\prime}=1.85$ ), and only slightly lower at Noggin Pass (27 MUs, $\left.H^{\prime}=1.81\right)$. Diversity was lower at both Viper Reef sites (24 MUs, $H^{\prime}=1.35$ for Viper North; $26 \mathrm{MUs}, H^{\prime}=1.60$ for Viper South).

ANOSIM indicated significant variation in SBM abundance between all 3 sites (Table 1). Noggin Pass and Hydrographers Passage were more similar to each other than to Viper Reef. The 2 adjacent surveys at Viper Reef were more similar to each other than any other combination of sites, although the variation was still significant (Table 1). SIMPER indicated that the

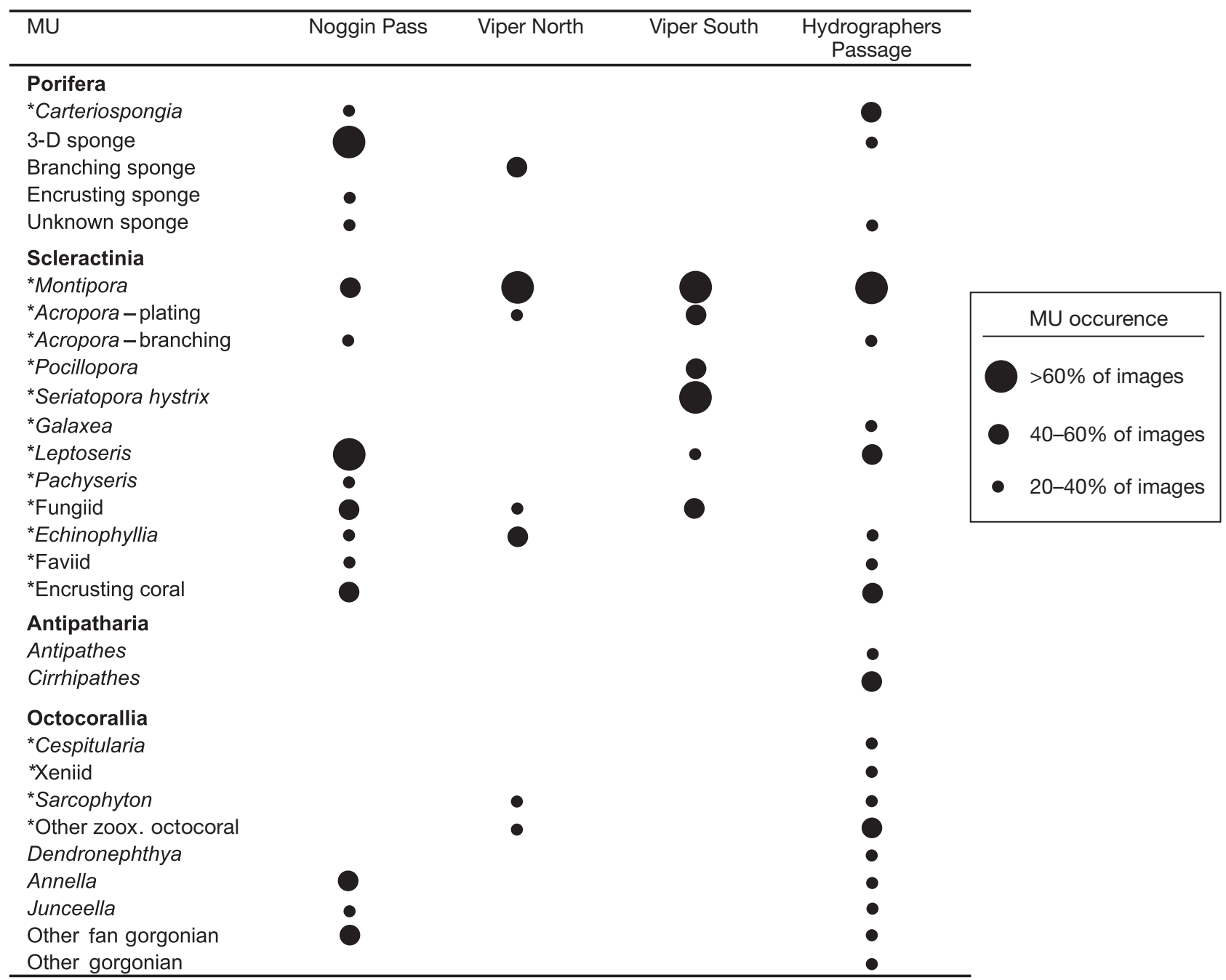

Fig. 3. Abundance of morphological units (MUs) in each autonomous underwater vehicle (AUV) survey. Circles: percentage of images in which each MU occurred, with larger circles representing higher percentage of images (MUs occurring in $<20 \%$ of images in all 4 AUV surveys not shown). Zoox.: zooxanthellate; *phototrophic taxon 
Table 2. Summary of biotic and abiotic variables for the 7 image groups (based on their sessile benthic megafauna, SBM) identified using cluster analysis. Mean $( \pm$ SD) percent cover values for morphological units (MUs) and substrata, calculated using the relative abundance scale described in 'Materials and methods'. Percent cover for any given score was considered as the mid-point for that category; a score of 5 in the data matrix was therefore estimated to represent $90 \%$ cover of that MU/substrate. MUs/substrata with percent cover $<2 \%$ not shown. +: abundances of 2 to $4 \%$. ${ }^{*}$ phototrophic taxon. Diversity $\left(H^{\prime}\right)$ : calculated for all sites within the group combined. Zoox.: zooxanthellate

\begin{tabular}{|c|c|c|c|c|c|c|c|}
\hline Morphological unit & 1 & 2 & 3 & 4 & 5 & 6 & 7 \\
\hline No. images & 41 & 11 & 5 & 7 & 10 & 12 & 14 \\
\hline \multicolumn{8}{|l|}{ Porifera } \\
\hline${ }^{*}$ Carteriospongia & & & & $23(15)$ & & & $6(8)$ \\
\hline Ianthella & & & & & & + & \\
\hline 3-D sponge & & + & & & & $4(6)$ & + \\
\hline Branching sponge & & + & + & & & & \\
\hline Unknown sponge & & & & + & & + & \\
\hline \multicolumn{8}{|l|}{ Scleractinia } \\
\hline${ }^{*}$ Montipora & $29(19)$ & $22(18)$ & $7(7)$ & $15(6)$ & $10(18)$ & $5(6)$ & + \\
\hline${ }^{*}$ Acropora - plating & + & & & + & & & \\
\hline $\begin{array}{l}\text { *Acropora - branching } \\
{ }^{*} \text { Pocillopora }\end{array}$ & + & & & $4(3)$ & & & \\
\hline${ }^{*}$ Seriatopora hystrix & + & & & + & & & \\
\hline *Galaxea & & & $48(16)$ & $5(7)$ & & & \\
\hline${ }^{*}$ Leptoseris & & $6(5)$ & & + & $4(6)$ & $4(5)$ & + \\
\hline${ }^{*}$ Pachyseris & & + & & & & + & \\
\hline${ }^{*}$ Fungiid & + & & & & + & + & \\
\hline${ }^{*}$ Echinophyllia & & $11(16)$ & & & & & + \\
\hline${ }^{*}$ Faviid & & + & & & & & \\
\hline${ }^{*}$ Encrusting coral & & $4(4)$ & & + & $22(12)$ & + & \\
\hline \multicolumn{8}{|l|}{ Antipatharia } \\
\hline Antipathes & & & & & $13(23)$ & & \\
\hline Cirrhipathes & & & + & + & & & \\
\hline \multicolumn{8}{|l|}{ Octocorallia } \\
\hline${ }^{*}$ Cespitularia & & & + & $4(4)$ & & & \\
\hline${ }^{*}$ Sarcophyton & & & & + & & & \\
\hline${ }^{*}$ Sinularia & & & & + & & & \\
\hline${ }^{*}$ Xeniid & & & & $7(9)$ & & & \\
\hline${ }^{*}$ Other zoox. octocoral & & & & $5(3)$ & & & \\
\hline Annella & & & & & & $18(14)$ & \\
\hline Junceella & & & & $4(3)$ & & + & \\
\hline Fan gorgonian & & & & + & $7(8)$ & + & \\
\hline Other gorgonian & & & & & & + & + \\
\hline \multicolumn{8}{|c|}{ Abiotic variables (mean values) } \\
\hline Rugosity index $(R I)$ & 1.2 & 1.5 & 1.4 & 1.2 & 1.6 & 1.5 & 1.3 \\
\hline Slope $(S)\left({ }^{\circ}\right)$ & 20.3 & 37.7 & 17.8 & 15.4 & 49.5 & 43.0 & 30.4 \\
\hline Sand $(\%)$ & + & + & + & + & + & 8 & 8 \\
\hline Gravel (\%) & & & & & + & 12 & 6 \\
\hline Rubble (\%) & & & & & & 5 & + \\
\hline $\begin{array}{l}\text { Sediment-covered } \\
\text { limestone }(\%)\end{array}$ & 6 & 3 & 11 & 60 & 7 & 21 & 29 \\
\hline Limestone (\%) & 82 & 84 & 83 & 42 & 83 & 52 & 52 \\
\hline Diversity $\left(H^{\prime}\right)$ & 1.5 & 1.8 & 1.3 & 2.4 & 1.6 & 1.9 & 1.6 \\
\hline MU richness & 32 & 23 & 9 & 26 & 20 & 21 & 32 \\
\hline
\end{tabular}

and Annella (Noggin vs. Viper), Montipora and Carteriospongia (Noggin vs. Hydrographers and Viper vs. Hydrographers). Variation in the relative abundance of Montipora explained $12.5 \%$ of the observed dissimilarity between the 2 Viper Reef surveys.

Cluster analysis on the 'reef' images (25 from each site) suggested 7 image groups based on their SBM (Table 2). Groups 1 (Montipora community) and 4 (Carteriospongia) were dominated by diverse phototrophic taxa, including various corals, zooxanthellate octocorals and phototrophic sponges. Group 2 (Echinophyllia) was characterised by corals from the family Agariciidae; although Montipora was commonly observed, it was not as dominant as in Group 1. Groups 5 (Azooxanthellate octocorals) and 6 (Annella) were dominated by heterotrophic suspension-feeding taxa in addition to Montipora and Leptoseris. Group 3 (Galaxea) was dominated by large colonies of the coral Galaxea but consisted of only 5 images, while Group 7 was a non-conformist group based on shared absences of most MUs.

Most image groups were found predominantly at only 1 site (Fig. 5a). The Montipora and Galaxea communities were common at both Viper Reef sites, while the Annella community was found exclusively at Noggin Pass. Hydrographers Passage was the most heterogeneous site, recording 6 of the 7 groups, including all of the Carteriospongia group images and most of the Azooxanthellate octocorals group. BIOENV indicated the variables slope, water clarity, and chlorophyll best explained the observed variation in the relative abundances of megafauna across the 4 sites $(\rho=0.458)$. Interrelationships among the predictors and communities are indicated in Fig. 5b. The influence of slope is revealed by the occurrence of heterotroph-dominated communities on the right of the figure (steep slopes), while autotrophmost important contributors to the observed variation were Montipora, Annella and Carteriospongia. Differences in the abundance of Montipora in combination with one other taxon explained 15 to $22 \%$ of the differences in all pairwise comparisons of sites: Montipora dominated communities (Montipora and Galaxea) occur to the left. The lower central position of the Carteriospongia community in Fig. 5 possibly reflects its mixotrophic capacities in waters of higher productivity (see Chlorophyll vector in Fig. 5b). 

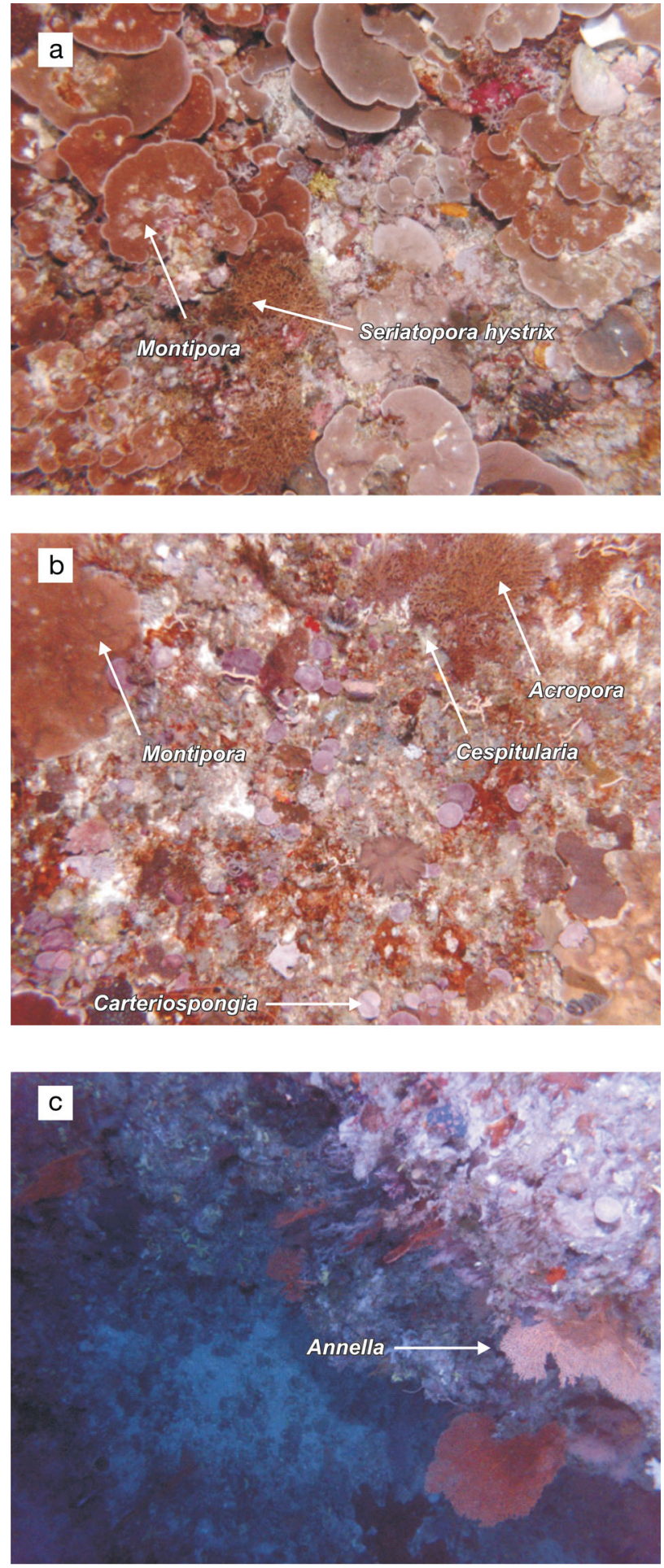

Fig. 4. Representative autonomous underwater vehicle (AUV) images showing communities characteristic of each study area: (a) community heavily dominated by scleractinian corals at Viper Reef; (b) diverse phototrophic community occurring on flat reef top at Hydrographers Passage; and (c) steep wall with abundant colonies of Annella at Noggin Pass
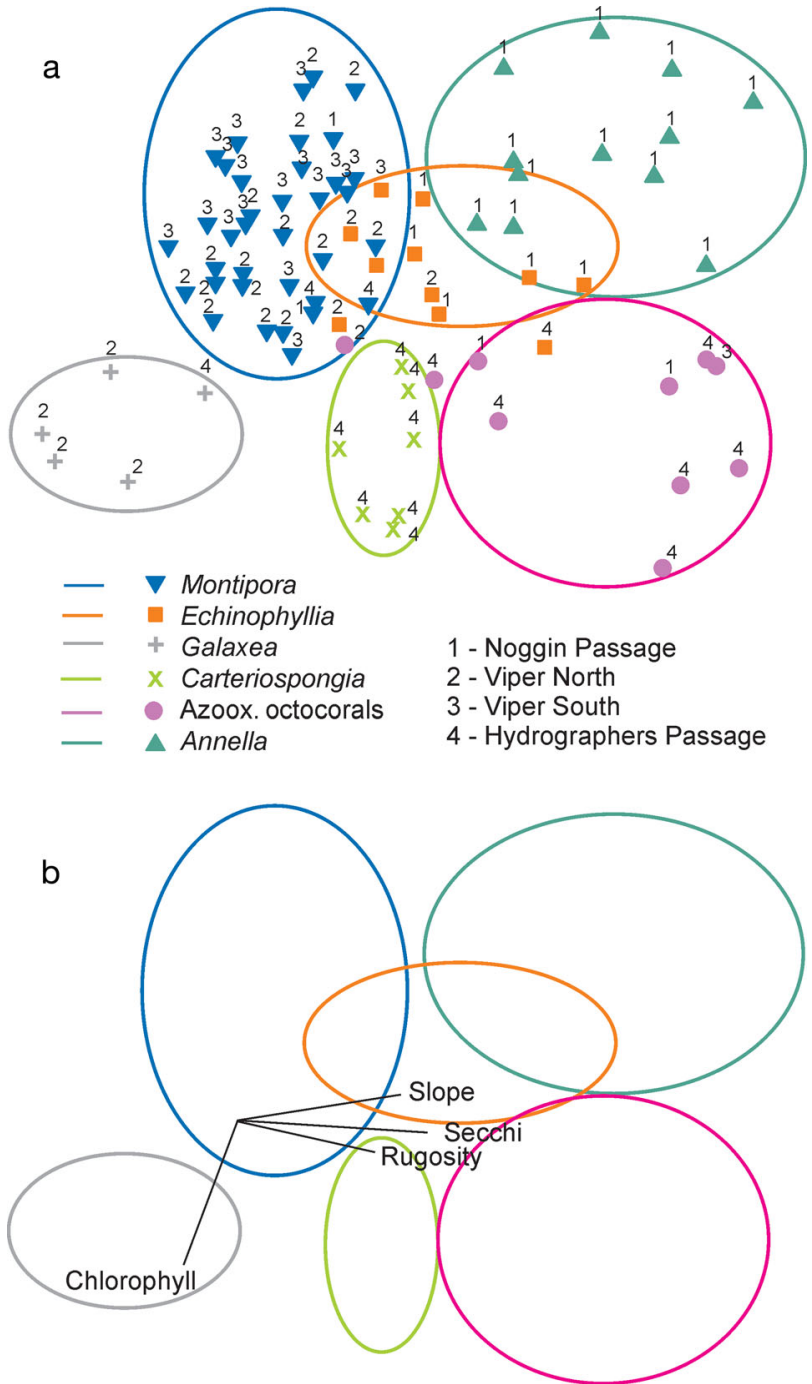

Fig 5. Multidimensional scaling diagram showing distribution of image groups based on relative abundance of sessile benthic macrofauna relative to environmental variables. Colours: image groups identified in cluster analysis; (a) Sites: 1 = Noggin Pass, 2 = Viper North, 3 = Viper South, 4 = Hydrographers Passage. Group 7 (non-conformist group) not shown. (b) Location of image groups relative to explanatory environmental variables (only vectors with Spearman rank correlation $>0.5$ are shown). Azoox.: azooxanthellate

\section{DISCUSSION}

\section{Site-scale community structure}

Not surprisingly, the best predictor of the presence of SBM at the site scale was the presence of reef substrate, which clearly contained the highest abundance and diversity of SBM. However, the overwhelming abundance of non-reef substrata in the random sitescale sampling was not suitable to identify explanatory variables other than substrate type. Nonetheless, these 
results show that submerged reefs of the GBR shelfedge, formed by shallow-water coral communities during lower sea levels, now provide important habitat for MCE communities. The varying patterns of algal abundances on non-reef substrates between sites may reflect variations in localised upwelling and nutrient availability at different sites. The presence of Halimeda fields to $96 \mathrm{~m}$ depth in the central GBR (Drew \& Abel 1988) was attributed to localised upwelling of nutrients onto the continental shelf, and Leichter et al. (2008) report similarly dense macroalgal communities at 50 to $60 \mathrm{~m}$ adjacent to the Florida Keys. Although the Halimeda fields observed at 55 to $60 \mathrm{~m}$ depth at Viper Reef did not correlate with higher surface chlorophyll, the reduced water clarity may indicate localised upwelling. In addition to encouraging algal growth, nutrient availability could be an important control on SBM community composition on reef substrates. Species richness of heterotrophic octocorals on the shallow-water GBR is closely correlated with areas of high water-column productivity (Fabricius \& De'ath 2008). Interestingly, very few heterotrophic suspension-feeders were observed at either Viper Reef site. There is also evidence that phototrophic corals may increase reliance on heterotrophy in nutrient-rich or light-limited environments (e.g. Anthony \& Fabricius 2000, Leichter \& Genovese 2006), although this is poorly quantified.

\section{Community composition on 'reef' substrata}

This study revealed a consistent pattern of phototrophic taxa inhabiting the flatter tops of reefs and heterotrophic suspension-feeders occurring on steeper slopes. Light limitation is, by definition, an important factor driving MCE community structure (e.g. Kahng \& Kelley 2007, Kahng et al. 2010), and the limiting effects of low ambient light levels at these depths may be exacerbated by relatively small increases in slope. The few obligate phototrophs that did occur on steeper slopes represent taxa commonly reported from MCEs elsewhere in the Indo-Pacific (Kahng et al. 2010), and probably have either a very broad ecological niche enabling them to survive in an extremely wide range of habitats (e.g. Montipora) or are 'MCE specialists' (e.g. Leptoseris), which possess specific adaptations to low light environments (Fricke et al. 1987).

Sedimentation has been shown to be an important control on growth of phototrophic taxa (e.g. Van Woesik \& Done 1997, Fabricius 2005), particularly in inshore areas. Flat substrata in low flow areas are prone to sedimentation, limiting both the settlement of new recruits and the survival of established colonies (Fabricius 2005). Although MCEs generally occur in clear oceanic environments (Kahng et al. 2010), there is evidence that sediment downwelling may be an important factor in their community composition in some areas (Colin et al. 1986, Bridge et al. 2010). Many corals in mesophotic habitats adopt flattened morphologies to better intercept light (e.g. Jaubert 1977 , Wallace 1978); however, this increases their vulnerability to sedimentation. Plating Montipora, which was abundant in this study, are particularly poor at removing sediment from their surface (Stafford-Smith \& Ormond 1992). This may contribute to the occurrence of phototrophs on the tops of reef pinnacles, where they receive not only sufficient photosynthetically active radiation (PAR), but are also kept free of sediment. Heterotrophic, suspension-feeding taxa not dependent on light would be better able to utilise steep habitats less vulnerable to sedimentation.

Despite the consistent patterns in the distribution of functional groups, there were substantial variations in community composition between sites. These patterns may reflect variations in oceanographic conditions at each site, the ecology and life histories of different taxa, or spatial autocorrelation not detectable without replicates at each site. However, some insights may be obtained by comparing the patterns observed on MCEs to adjacent shallow-water reefs. Phototroph communities at Viper Reef and Noggin Pass were heavily dominated by corals (Fig. 4a), while Hydrographers Passage exhibited a higher diversity of phototrophic taxa including zooxanthellate octocorals (particularly Cespitularia) as well as corals (Fig. 4b). The emergent reefs near Hydrographers Passage (along with the southern Swain Reefs) contain the highest diversity of Cespitularia in the GBR (e-atlas, modelled using data from Fabricius \& De'ath 2008), suggesting at least some observations in this study may reflect broad-scale distribution patterns rather than within-site differences.

Community composition for heterotrophs was similarly variable. Steep walls at Hydrographers Passage were colonised by a variety of heterotrophic octocoral taxa as well as Antipathes, whereas similar habitats at Noggin Pass were dominated by Annella (Fig .4c). Although heterotrophic octocoral taxa show relatively homogeneous habitat requirements (Fabricius \& De'ath 2008), many exhibit limited ranges and/or patchy distributions within the GBR. This is probably caused by settlement of negatively-buoyant brooded larvae only a few metres from the parent colony (Fabricius \& Alderslade 2001). The ability of a wide range of taxa to utilise similar habitat combined with limited dispersal ability may cause significant heterogeneity in community composition on relatively small scales (metres to tens of metres) as well as between sites. Unfortunately, given the lack of replicates at each site, 
it is not possible to disentangle such small-scale, within-site variation from regional patterns.

Richness of heterotrophic octocoral taxa is strongly correlated with depth, current flow, slope and a lack of wave action, resulting in richness being highest in deep waters with high productivity where competition with phototrophs is less intense. In the GBR lagoon these conditions occur along inshore regions of the northern GBR (Fabricius \& De'ath 2008). However, much more extensive areas with similar environmental conditions may also occur on many of the submerged reefs, particularly at Hydrographers Passage. At the depths examined in this study, the flat reef tops still receive enough light to allow competition from phototrophs. However steep walls and also deeper submerged reefs (described to $147 \mathrm{~m}$ depth in Bridge et al. 2010) may provide a habitat perfectly suited to heterotrophic octocorals.

\section{Implications for GBR and Indo-Pacific MCEs}

The development of tools to assess MCEs at large spatial scales using physical and environmental proxies is an important factor in overcoming current knowledge gaps regarding the nature and distribution of MCEs. The use of remotely-sensed data is particularly important on the GBR, where MCEs occur far offshore, and restrictive diving legislation makes obtaining samples difficult. The vast majority of SBM taxa occur on 'reef' substrates, and community structure is heavily influenced by fine-scale (dm to $\mathrm{m}$ ) topography. Predictive modelling of SBM communities on GBR MCEs would therefore require bathymetry and side-scan sonar data of sufficient resolution to detect topographic and substrate changes at these scales. This would be made possible by the collection of high-resolution (up to $5 \times 5 \mathrm{~m}$ ) multibeam and backscatter reflectivity data. However, the highest resolution digital depth models currently available for the GBR are $250 \times 250 \mathrm{~m}$ (Lewis 2001). Large scale modelling of GBR MCEs in areas without high-resolution AUV (or equivalent) data would require an understanding of mesoscale (10s to $100 \mathrm{~s} \mathrm{~km})$ variations in MCE biodiversity. For this purpose, representative replicated sampling is needed, and such sampling needs to be stratified to account for the local scale patterns, which were difficult to determine in the present study. However, should such data be collected, it would no doubt be of significant interest to managers of the GBR Marine Park.

This study has demonstrated that diverse MCE communities occur for at least $500 \mathrm{~km}$ along the GBR shelfedge. Given that submerged reefs have been documented occurring continuously from the Ribbon Reefs $\left(15^{\circ} \mathrm{S}\right)$ to the southern edge of the Swain Reefs $\left(23^{\circ} \mathrm{S}\right.$,
350 km south-east of Hydrographers Passage) (Tilbrook \& Matear 2008) as well as in the far northern GBR $\left(10^{\circ} \mathrm{S}\right.$, and Gulf of Papua) (Harris et al. 2005), mesophotic reef communities probably exist for $>1700 \mathrm{~km}$ along the GBR shelf-edge. The presence of diverse octocoral communities as well as large plating coral colonies supports the view that the submerged reefs are rarely subjected to disturbances such as storms and bleaching events. Although tropical cyclones are relatively common at all 3 sites (Massel \& Done 1993), storms of sufficient magnitude to affect community structure at these depths are probably extremely rare. Massel \& Done (1993) demonstrate that even as shallow as $12 \mathrm{~m}$, waves and currents strong enough to dislodge massive corals are so rare that corals have a high probability of reaching 50 to $100 \mathrm{yr}$ old (unless they are killed by some other means). In addition, their location several $\mathrm{km}$ offshore of emergent reefs means they would not be subjected to storm debris avalanches, such as those observed decimating mesophotic reef habitats in French Polynesia (Harmelin-Vivien \& Laboute 1986). The presence of large colonies of both corals and heterotrophic octocorals at all sites suggests these reefs have not been affected by cyclone damage for many years, lending support to the hypothesis that MCEs may be important refugia for coral reef fauna. With shallow-water reefs under increasing pressure from both direct anthropogenic impacts and climate change, MCEs may become increasingly important to the health and resilience of coral reef ecosystems both in the GBR and elsewhere. Given these results, GBR MCEs deserve further study not only on their sessile benthic megafauna, but also on their fish and mobile invertebrate communities.

Acknowledgements. We thank the captain and crew of the RV 'Southern Surveyor' for their outstanding work on the cruise. The project was funded by the Australian Marine National Facility, the Integrated Marine Observing System, the National Geographic Society, the Natural Environment Research Council, the Great Barrier Reef Marine Park Authority's Science for Management Awards, and the School of Earth and Environmental Science, James Cook University. We gratefully acknowledge the assistance of A. Edwards with regard to preparing figures. R.B. acknowledges a Queensland Smart Futures Fellowship for salary support. We also thank K. Fabricius and C. Battershill at the Australian Institute of Marine Science and C. Wallace and P. Muir at the Queensland Museum for assistance with taxonomy. S. Smithers, A. Stypel, A. Brazenor, S. Hansen and M. Kramer are thanked for their valuable assistance, as are 3 anonymous reviewers for their helpful comments, which significantly improved the manuscript.

\section{LITERATURE CITED}

Anthony K, Fabricius K (2000) Shifting roles of heterotrophy and autotrophy in coral energetics under varying turbi- 
dity. J Exp Mar Biol Ecol 252:221-253

Armstrong RA, Singh H, Torres J, Nemeth RS and others (2006) Characterizing the deep insular shelf coral reef habitat of the Hind Bank marine conservation district (US Virgin Islands) using the Seabed autonomous underwater vehicle. Cont Shelf Res 26:194-205

Bare AY, Grimshaw KL, Rooney JJ, Sabater MG, Fenner D, Carroll B (2010) Mesophotic communities of the insular shelf at Tutuila, American Samoa. Coral Reefs 29:369-377

Beaman RJ, Harris PT (2007) Geophysical variables as predictors of megabenthos assemblages from the northern Great Barrier Reef, Australia. In: Todd BJ, Greene HG (eds) Mapping the seafloor for habitat characterisation. Geol Assoc Can, Spec Pap 47, St Johns, p 247-264

Beaman RJ, Webster JM, Wust RAJ (2008) New evidence for drowned shelf edge reefs in the Great Barrier Reef, Australia. Mar Geol 247:17-34

Bongaerts P, Ridgway T, Sampayo EM, Hoegh-Guldberg O (2010) Assessing the 'deep reef refugia' hypothesis: focus on Caribbean reefs. Coral Reefs 29:309-327

Bridge TCL, Done TJ, Beaman RJ, Friedman A, Williams SB, Pizarro O, Webster JM (2010) Topography, substratum and benthic macrofaunal relationships on a tropical mesophotic shelf margin, central Great Barrier Reef, Australia. Coral Reefs 30:143-153

Clarke KR, Gorley RN (2006) PRIMER v6: user manual/ tutorial. PRIMER-E: Plymouth

Clarke KR, Warwick RM (2001) Changes in marine communities: an approach to statistical analysis and interpretation. PRIMER-E, Plymouth

Colin PL (1986) Benthic community distribution in the Enewetak Atoll lagoon, Marshall Islands. Bull Mar Sci 38: 129-143

Colin PL, Devaney DM, Hillis-Colinvaux L, Suchanek TH, Harrison JT III (1986) Geology and biological zonation of the reef slope, 50-360 $\mathrm{m}$ depth at Enewetak Atoll, Marshall Islands. Bull Mar Sci 38:111-128

De'ath G (2007) The spatial, temporal and structural composition of water quality of the Great Barrier Reef, and indicators of water quality and mapping risk. Report to the Australian Government's Marine and Tropical Sciences Research Facility. Reef and Rainforest Research Centre, Cairns

Dinesen ZD (1983) Patterns in the distribution of soft corals across the central Great Barrier Reef. Coral Reefs 1: $229-236$

> Done TJ (1982) Patterns in the distribution of coral communities across the central Great Barrier Reef. Coral Reefs 1: 95-107

> Drew EA, Abel KM (1988) Studies on Halimeda I. The distribution and species composition of Halimeda meadows throughout the Great Barrier Reef province. Coral Reefs 6:195-205

Fabricius KE (2005) Effects of terrestrial runoff on the ecology of corals and coral reefs: review and synthesis. Mar Pollut Bull 50:125-146

Fabricius KE, Alderslade P (2001) Soft corals and sea fans: a comprehensive guide to the tropical shallow-water genera of the central-west Pacific, the Indian Ocean and the Red Sea. Australian Institute of Marine Science, Townsville

Fabricius KE, De'ath G (2008) Photosynthetic symbionts and energy supply determine octocoral biodiversity in coral reefs. Ecology 89:3163-3173

> Fricke HW, Vareschi E, Schlichter D (1987) Photoecology of the coral Leptoseris fragilis in the Red Sea twilight zone (an experimental study by submersible). Oecologia 73: $371-381$
Friedman A, Pizarro O, Williams SB (2010) Rugosity, slope and aspect from bathymetric stereo image reconstructions. Oceans 2010 IEEE, Sydney doi:10.1109/OCEANSSYD.2010. 5604003. Available at: http://ieeexplore.ieee.org/stamp/ stamp.jsp?tp=\&arnumber $=5604003$ \&isnumber $=5603506$

> Harmelin-Vivien ML, Laboute P (1986) Catastrophic impact of hurricanes on atoll outer reef slopes in the Tuamotu (French Polynesia). Coral Reefs 5:55-62

> Harris PT, Davies PJ (1989) Submerged reefs and terraces on the shelf edge of the Great Barrier Reef, Australia: morphology, occurrence and implications for reef evolution. Coral Reefs 8:87-98

Harris PT, Heap A, Passlow V, Hughes M, Daniell J, Hemer M, Anderson O (2005) Tidally incised valleys on tropical carbonate shelves: an example from the northern Great Barrier Reef, Australia. Mar Geol 220:181-204

Hinderstein LM, Marr JCA, Martinez FA, Dowgiallo MJ and others (2010) Theme section on 'mesophotic coral ecosystems: characterization, ecology and management'. Coral Reefs 29:247-251

Hopley D (2006) Coral Reef growth on the shelf margin of the Great Barrier Reef with special reference to the Pompey Complex. J Coast Res 22:150-158

Hopley D, Graham TL, Rasmussen CE (1997) Submerged shelf-edge reefs, coral reefs, Great Barrier Reef Australia, PACON 96. Recent Advances in Marine Science and Technology, Honolulu, HI, p 305-315

Hopley D, Smithers SG, Parnell KE (2007) The geomorphology of the Great Barrier Reef: development, diversity and change. Cambridge University Press, Cambridge

Jaubert JM (1977) Light, metabolism and growth forms of the hermatypic scleractinian coral Synaraea convexa Verrill in the lagoon of Moorea (French Polynesia). In: Taylor DL (ed) Proc 3rd Int Coral Reef Symp, Miami, 1:483-488

Johnson-Roberson M, Pizarro O, Williams SB (2010) Generation and visualization of large scale $3 \mathrm{D}$ reconstructions from underwater robotics surveys. J Field Robot 27: 21-51

Kahng SE, Kelley CD (2007) Vertical zonation of megabenthic taxa on a deep photosynthetic reef (50-140 m) in the Au'au Channel, Hawaii. Coral Reefs 26:679-687

Kahng SE, Garcia-Sais JR, Spalding HL, Brokovich E and others (2010) Community ecology of coral reef ecosystems. Coral Reefs 29:255-275

> Kostylev VE, Todd BJ, Fader GBJ, Courtney RC, Cameron GDM, Pickrill RA (2001) Benthic habitat mapping on the Scotian shelf based on multibeam bathymetry, surficial geology and sea floor photographs. Mar Ecol Prog Ser 219: 121-137

Leichter JL, Genovese SJ (2006) Intermittent upwelling and subsidized growth of the scleractinian coral Madracris mirabilis on the deep fore-reef slope of Discovery Bay, Jamaica. Mar Ecol Prog Ser 316:95-103

Leichter JL, Stokes MD, Genovese SJ (2008) Deep water macroalgal communities adjacent to the Florida Keys reef tract. Mar Ecol Prog Ser 356:123-138

Lewis A (2001) Great Barrier Reef depth and elevation model. CRC Tech Rep No. 33, CRC Reef Research Centre, Townsville

Locker SD, Armstrong RA, Battista TA, Rooney JJ, Sherman C, Zawada DG (2010) Geomorphology of mesophotic coral ecosystems: current perspectives on morphology, distribution, and mapping strategies. Coral Reefs 29:329-345

Mahon I, Williams SB, Pizarro O, Johnson-Roberson M (2008) Efficient view-based SLAM using visual loop closures. IEEE Trans Robot 24:1002-1014

Maragos JE, Jokiel PL (1986) Reef corals of Johnston Atoll: 
one of the world's most isolated reefs. Coral Reefs 4: $141-150$

Massel SR, Done TJ (1993) Effects of cyclone waves on massive coral assemblages on the Great Barrier Reef: meteorology, hydrodynamics, and demography. Coral Reefs 12:153-166

Mumby PJ, Skirving W, Strong AE, Hardy JT and others (2004) Remote sensing of coral reefs and their physical environment. Mar Pollut Bull 48:219-228

Pitcher CR, Doherty P, Arnold P, Hooper J and others (2007) Seabed biodiversity on the continental shelf of the Great Barrier Reef world heritage area. CSIRO Marine and Atmospheric Research, Cleveland

Stafford-Smith MG, Ormond RFG (1992) Sediment-rejection mechanisms of 42 species of Australian scleractinian corals. Aust J Mar Freshwater Res 43:683-705

Tilbrook B, Matear R (2008) Carbon chemistry of the Great Barrier Reef. RV 'Southern Surveyor' voyage summary. Marine National Facility, Hobart, Tasmania, available at www.marine.csiro.au/nationalfacility/voyagedocs/2008/ MNF_SS09-08_sum.pdf

Van Woesik R, Done TJ (1997) Coral communities and reef growth in the southern Great Barrier Reef. Coral Reefs 16:103-115
Veron JEN (1995) Corals in space and time: the biogeography and evolution of the scleractinia. UNSW Press, Sydney

Wallace CC (1978) The coral genus Acropora (Scleractinia: Astrocoeniina: Acroporidae) in the central and southern Great Barrier Reef province. Mem Queensl Mus 18: 273-319

Webster JM, Davies PJ, Beaman RJ, Williams SB, Byrne M (2008) Evolution of drowned shelf-edge reefs in the GBR: implications for understanding abrupt climate change, coral reef response and modern deep water benthic habitats - RV 'Southern Surveyor', voyage summary. Marine National Facility, Hobart, Tasmania, available at www.marine.csiro.au/national-facility/voyagedocs/2007/ summarySS07-2007.pdf

Williams SB, Pizarro O, Webster I, Beaman JM, Mahon RJ, Johnson-Roberson M, Bridge TCL (2010) AUV-assisted surveying of drowned reefs on the shelf edge of the Great Barrier Reef, Australia. J Field Robot 27:675-697

Wolanski E (1994) Physical oceanographic processes of the Great Barrier Reef. CRC Press, Boca Raton, FL

Wright DJ, Lundblad ER, Larkin EM, Rinehard RW, Murphy J, Cary-Kothera L, Draganov K (2005) ArcGIS benthic terrain modeller. Oregon State University, Corvallis, OR

Appendix 1. Morphological units (MUs) used for data collection for this study. Rare taxa ( $<2 \%$ occurrence) were removed prior to statistical analysis; therefore, greater taxonomic detail (more MUs) were used on 'reef' substrata (Table A2) compared to site-scale habitats (Table A1)

Table A1. MUs used in site-scale habitat analysis

\begin{tabular}{|ll|}
\hline Morphological unit (MU) & Morphological unit (MU) \\
\hline Porifera & Antipatharia \\
Branching sponge & Antipathes \\
Light brown thinly branching sponge & Cirrhipathes \\
Carteriospongia & Octocorallia \\
Other sponge & Cespitularia \\
Unknown sponge & Xeniid \\
& Zooxanthellate octocoral \\
Scleractinia & Anella \\
Montipora & Branching ellisellid \\
Seriatopora hystrix & Unidentified gorgonian/axanthellate octocorals \\
Branching coral & Whip gorgonian \\
Fungiid & Fan gorgonian \\
Diaseris & Crinoidea \\
Faviid & Crinoid \\
Goniopora & \\
Leptoseris & Ascideacea \\
Encrusting croral & Ascidean \\
Plating coral & \\
Other coral & \\
\hline
\end{tabular}


Table A2. MUs used in classification of 'reef' substrata

\begin{tabular}{|c|c|}
\hline Morphological unit (MU) & Morphological unit (MU) \\
\hline Sponges & Antipatharia \\
\hline Carteriospongia & Antipathes \\
\hline Ianthella & Cirrhipathes \\
\hline \multicolumn{2}{|l|}{ 3-D sponge } \\
\hline Branching sponge & Octocorallia \\
\hline Encrusting sponge & Cespitularia \\
\hline \multirow[t]{2}{*}{ Unknown sponge } & Tubipora \\
\hline & Dendronephthya \\
\hline Scleractinia & Sarcophyton \\
\hline Montipora & Sinularia \\
\hline Acropora - plating & Xeniid \\
\hline Acropora - branching & Annella \\
\hline Pocillopora & Branching ellisellid \\
\hline Seriatopora hystrix & Junceella \\
\hline Euphyllidae & Other soft coral \\
\hline Galaxea & Fan gorgonian \\
\hline Leptoseris & Other gorgonian \\
\hline \multicolumn{2}{|l|}{ Pachyseris } \\
\hline Fungiid & Actiniaria \\
\hline Echinophyllia & Heteractis crispa \\
\hline \multicolumn{2}{|l|}{ Mycedium } \\
\hline Blastomussa & Crinoidea \\
\hline Scolymia & Crinoid \\
\hline \multicolumn{2}{|l|}{ Faviid } \\
\hline Goniopora & Ascideacea \\
\hline Encrusting coral & Ascidian \\
\hline
\end{tabular}

Editorial responsibility: Hans Heinrich Janssen, Oldendorf/Luhe, Germany
Submitted: August 27, 2010; Accepted: January 19, 2011 Proofs received from author(s): March 26, 2011 